\title{
Editorial:
}

\section{Long-term Care Reform and "Family" Care: A Worrisome Combination}

Across Canada, there is a shift from an institution-centred long-term care system to one that is community-based. Although, in the abstract, one might well view this shift with enthusiasm, the suspicion that it is being driven primarily by economic rather than humanitarian reasons leads to some serious concerns. An overriding concern is that women, who make up the vast majority of family caregivers, will be expected to provide even greater amounts of care than they have in the past and will be even further exploited by this "reformed" system than by the system that preceded it (see Bornstein, 1994). Long-term care reform, by transferring more caregiving work to families, holds many pitfalls. In this context, I will consider three issues that relate to family care and that will increase in salience as long-term care reform proceeds: combining paid employment and caring for older relatives; formal services; and institutionalization.

Combining paid employment with responsibilities for the care of an older relative is an increasingly common experience. To the extent that long-term care reform will entail more caregiving from families than is currently the case, we may assume that the experience of combining employment and caregiving may become more difficult as well as more common. The investigators who conducted the Canadian Study of Health and Aging (CSHA) report in this journal that 36 per cent of all informal primary caregivers were employed, a figure which represents over one million Canadians. And note that this figure did not include employed persons who are secondary caregivers. Other data come from a survey conducted by The Work and Eldercare Research Group (1993) of CARNET: The Canadian Aging Research Network. In that study 12 per cent of employed Canadians were helping an elderly relative with basic activities of daily living and spending an average of nine hours per week - the equivalent of a full work day - doing so.

The difficulty in combining employment and caregiving is evident in the CSHA's finding that one-third of employed caregivers reported disturbances in their work. The CARNET survey made similar findings. The one indicator of disruptions at work does not begin to capture the range and depth of difficulties that employed caregivers encounter, but it serves to make the point.

There may be some people who would advocate that women leave paid employment in order to provide care to older family members. That is emphatically not my view, but the more instructive point is that it does not appear to be the view of employed female caregivers themselves. The CSHA article reports that relatively small percentages of caregivers had termi- 
nated employment in order to care for their elderly relative. This is, however, an important issue and merits attention from both researchers and policy-makers. For example, the economic consequences for women who leave paid employment because of caregiving responsibilities should be a topic of future research and policy. As well, the fact that most employed caregivers continue in paid employment means that we need programs and policies that make it easier for caregivers to meet both work and family care responsibilities. These programs and policies must include but are by no means limited to the workplace. Moreover, we cannot rely on the goodwill or the ability of employers to provide all that is needed.

A second issue that worries me is that, as long-term care is "reformed," the shift away from an emphasis on institutional care will result in insufficient institutional beds. Although the current emphasis on keeping older people in the community is in keeping with the preferences of older people and their families, many old people - and their caregivers - reach a point at which institutionalization becomes appropriate. The danger is that, given the move to community care and the fiscal constraints that underlie it, sufficient high quality institutional "beds" will cease to be available.

The present policy shift to community care was, in part, fuelled by a finding some years ago that many persons in institutions had low levels of disability and were therefore "inappropriately" placed. This finding is cited today, as though it still described the institutional population. The CSHA article suggests, however, that the profile of persons in institutions has changed. On the whole, persons with little disability no longer seem to comprise a significant proportion of persons in institutions. Today, the age of admission is older, and the residents are much frailer and more often demented than was the case in the past. Policy must not be formulated or articulated today that is based on a profile of the institutionalized population of yesterday. If institutional beds are closed on the incorrect assumption that many current residents can manage in the community, we will have a new crisis, one in which the most disabled persons are left without the care they require.

We must not let institutions go "out of fashion". The component of the older population that increasingly makes up the institutional population the severely demented - is likely to increase in numbers. While community services may assist caregivers, they are unlikely to address the kinds of difficulties that ultimately lead to institutional placement. Therefore, we must ensure that placement remains a viable alternative. We will continue to need high quality and diverse types of institutions. We need facilities that are directed toward caring for demented elders. As well, we need to meet the needs of the important minority of persons in institutions who are severely physically disabled but cognitively intact. We must have facilities where these people can live in dignity, with co-residents with whom they can have normal social interaction.

A third aspect of long-term care reform that worries me concerns formal services. Providing sufficient services to community-dwelling disabled 
elders and their caregivers is supposed to be a central component of longterm care reform. I worry that services may not be "sufficient," and about what criteria will be used to determine sufficiency. I worry about eligibility criteria for services, about the quality of services, about availability, about barriers. Governments worry too, of course. For example, there has been a long-standing fear on the part of governments that the availability of formal services will lead to the substitution of formal care for informal, family care. The article in this journal by Judith Chipperfield adds an interesting dimension to research on this issue. Chipperfield found that older men were more likely to use primarily formal services once the availability of these services was increased, but this was not the case for women. This finding puzzles the investigator, since other findings in the study are not congruent with the notion of a substitution effect, but the finding does illustrate the need for continuing research (as well as pointing to the importance of gender differences). Until we gain a better understanding about why a substitution effect occurs for men, it would be premature to formulate policy initiatives. Continuing research on this issue is needed in order to provide a solid base on which to design policy.

Most researchers who study caregiving conclude that caregivers would benefit from formal services. Yet a recurring finding is that caregivers make little use of these services, although the reasons for this under-utilization have not yet been sufficiently investigated. The CSHA group found that close to half the caregivers of persons with dementia and over half the caregivers of persons with physical disability only used no services. We therefore need not only to ensure that sufficient services are available but also, as the CSHA investigators point out, that caregivers who could be helped by services actually use them.

Finally, it is useful to ask ourselves what kind of system we really want. In my opinion, ultimate responsibility for providing long-term care to older people should lie with government, in much the same way that responsibility for medical care currently does. Ideally, all older people would have their needs for care fully met without necessarily having to depend on other, mostly female, family members. Families could be confident that the elder's needs were being met by the formal system, with the family choosing the kind and amount of help they wished to provide. Some women might choose to provide quite extensive hands-on care, others might prefer to provide only emotional support, still others might wish to remain quite distant.

Why bother to iterate such an ideal in the current economic climate? Because rhetoric about "partnerships with families" or "helping families" transfers responsibility to the family, casts government in a supportive rather than central role, and creates a sense of inevitability about "necessary" changes. While the coming reality may fall short of the ideal, we do have some power to shape what form that reality will take, and to maintain an awareness of what we should be seeking.

We should not overestimate the availability or quality of family care. Some older people do not have family members who are able to provide care. 
Moreover, many caregivers are old themselves; over half the caregivers in the CSHA study were over age 60 and often had health problems of their own. Family care, even when available, is not always the best type of care from the perspective of the older recipient. This possibility tends to be completely ignored when policy seeks to transfer responsibility for the care of older persons to families (with the possible exception of the extreme failure of family care, elder abuse). Lynn Crawford, John Bond and Robert Balshaw, in their article in this journal, show that feelings of attachment are a predictor of help provision. But we need to remember that, while attachment may predict help provision, helping also occurs in the absence of feelings of attachment. We need to know more about the impact on the care recipient when family helping occurs under such circumstances. This knowledge will elude us if we continue to focus only on the amount of care (typically measured in terms of instrumental assistance). We need to move to an examination of the quality of family care, and to examine all aspects of care, including emotional support. Emotional support is the most widely reported type of help provided and received in families and is clearly important to people. Enabling families to provide emotional support is not usually considered a policy issue, perhaps because there is no direct counterpart in formal services. However, providing emotional support is a vitally important function of families and one that should not be undermined by over-burdening families with responsibility for the more practical types of support.

I have already expressed my view that responsibility for the long-term care of older members of Canadian society lies with government and that the extent of family involvement should be decided by families, not thrust upon them. Whatever the system that emerges, and whatever the options available, many women will continue to be caregivers. I do not believe we should actively promote the caregiving role for women. On the other hand, if women will assume this role we have a responsibility to ensure that they have the support they need. This means support in the workplace, support in the form of formal services, and support in the form of available and high quality institutions. Otherwise, long-term care reform will be a long-term sentence for women who provide care and for their older relatives who receive care.

\section{References}

Bornstein, J. (1994). Editorial: The Caregiving Dilemma. Canadian Journal on Aging, 13(2), 135-137.

The Work and Eldercare Research Group of CARNET (The Canadian Research Network). (1993). Work and Family: The Survey. Guelph: University of Guelph, Gerontology Research Centre.

Carolyn J. Rosenthal, University of Toronto 